\title{
The Effectiveness of Web-based Learning Media of Polyhedral for Students Grade 8
}

\author{
Pebrianto \& Tika Septia ${ }^{1}$ \\ SMUN 15 Mukomuko, Bengkulu, Indonesia \\ rianthegama@gmail.com \\ Mathematics Department, STKIP PGRI, Padang, West Sumatera, Indonesia ${ }^{1}$ \\ tikaseptia2589@gmail.com
}

\begin{abstract}
Students' difficulties in understanding polyhedral was one of the reasons for developing web-based learning media. This study is aimed at determining the effectiveness of webbased learning media for the students. The subjects of this study were students Grade 8 of SMPN 12 Mukomuko. An experimental method was adopted in this study and samples were divided into control and experimental groups. The control group was taught by conventional learning media while the experimental group was taught by web-based learning media. Pre-test and post-tests were administered to both groups. The findings showed that there is no significant mean difference between students' outcomes on the pretest and post-tests taught by conventional learning media, but there was a significant mean difference between the students' outcomes on the pre-test and post-tests taught with webbased learning media. The findings are encouraging and providing some promising directions, however, further study would be needed to determine if the results are due to the web-based approach or due to the teachers' enthusiasm, the novelty effect known as the Hawthorne Effect.
\end{abstract}

Keywords: effectiveness, web-based learning media, conventional learning media, geometry, polyhedral

\section{Introduction}

Web-based Instruction is becoming more important in the field of education as the education paradigm is changing, shifting the classroom initiatives from teachers to students (Ha, 2011, pp. 1-12). Internet is very useful in the field of education, especially as a medium of information that is packaged in the form of websites. It has great potential to improve the quality of teaching in schools, particularly in mathematics. Many things that are difficult, abstract, or imaginative can be presented to students through simulation on the internet, so teachers could use the internet to develop the mathematical learning process to empower their students.

Based on the observations done at SMPN12 Mukomuko, the student source of learning was limited to textbooks, worksheets, and materials presented by the teachers. The use of school facilities and infrastructure as learning media to support the learning process is still limited to the blackboard and display charts. SMPN 12 Mukomuko had its own computer laboratory connected to the internet network that could be accessed by its teachers and students. However, it was obvious that the use of the internet as a learning medium of mathematics had not been optimally utilized. The computer laboratory was only used while the teachers teaching information and communication technology (ICT). 
The results of interviews with students revealed that the mathematics was still considered difficult and unpleasant. One of the factors that make students have such opinion was teachers' lack of creativity in motivating students. One of the components that influences the effectiveness of learning mathematics is the selection of appropriate learning media. This is in accordance with the views expressed by Daryanto (2010, p. 5) who stated the use of media in the learning process could clarify the message without overuse of words, overcome the limitations of space and time, and excite student learning. Thus, the use of instructional media could provide improvement in the learning process.

The geometry topic of a flat side (two-dimensional shapes) has an important role in mathematics. This is because understanding the material of three-dimensional shapes on a higher level relies on a good grasp of the flat side (two-dimensional shapes) geometry material. The geometry of shapes is one of the subject of abstract mathematics and is difficult for students to understand the concepts. Student difficulties in understanding this material results in learning process which focuses only on finding numbers, formulas, charts, and pictures that makes the them less interested in mathematics.

This paper will briefly examine if the interactive web-based learning media of flat side (two-dimensional shapes) geometry involving a web-based activity can help students in understanding mathematics. Thus, this study examines the use of web-based learning media in SMPN 12 Mukomuko as a source of optimal learning in improving student learning outcomes.

\section{Methodology}

This study was conducted at SMPN 12 Mukomuko and the subjects were 50 students Grade 8. An experimental method was adopted in this study using experimental design pre-test and post-test control group design. The study used the same multiple choice test for both the pre-test and post-test. The pre-test was administered in order to establish the entry behavior of the students towards web-based learning media. The sample was divided into 24 for the control group and another 24 for the experimental group. Opportunity was given for the students to explore the websites at their own pace. The post-test was conducted in order to establish the effectiveness of web-based learning media.

Table 1.

Plan of the Design Research

\begin{tabular}{llll}
\hline Group & Pre-test & Treatment & Post-test \\
\hline Experiment & O1 & X1 & O2 \\
\hline Control & O3 & X2 & O4 \\
\hline
\end{tabular}

Flowchart of this study can be seen in the following figure. 


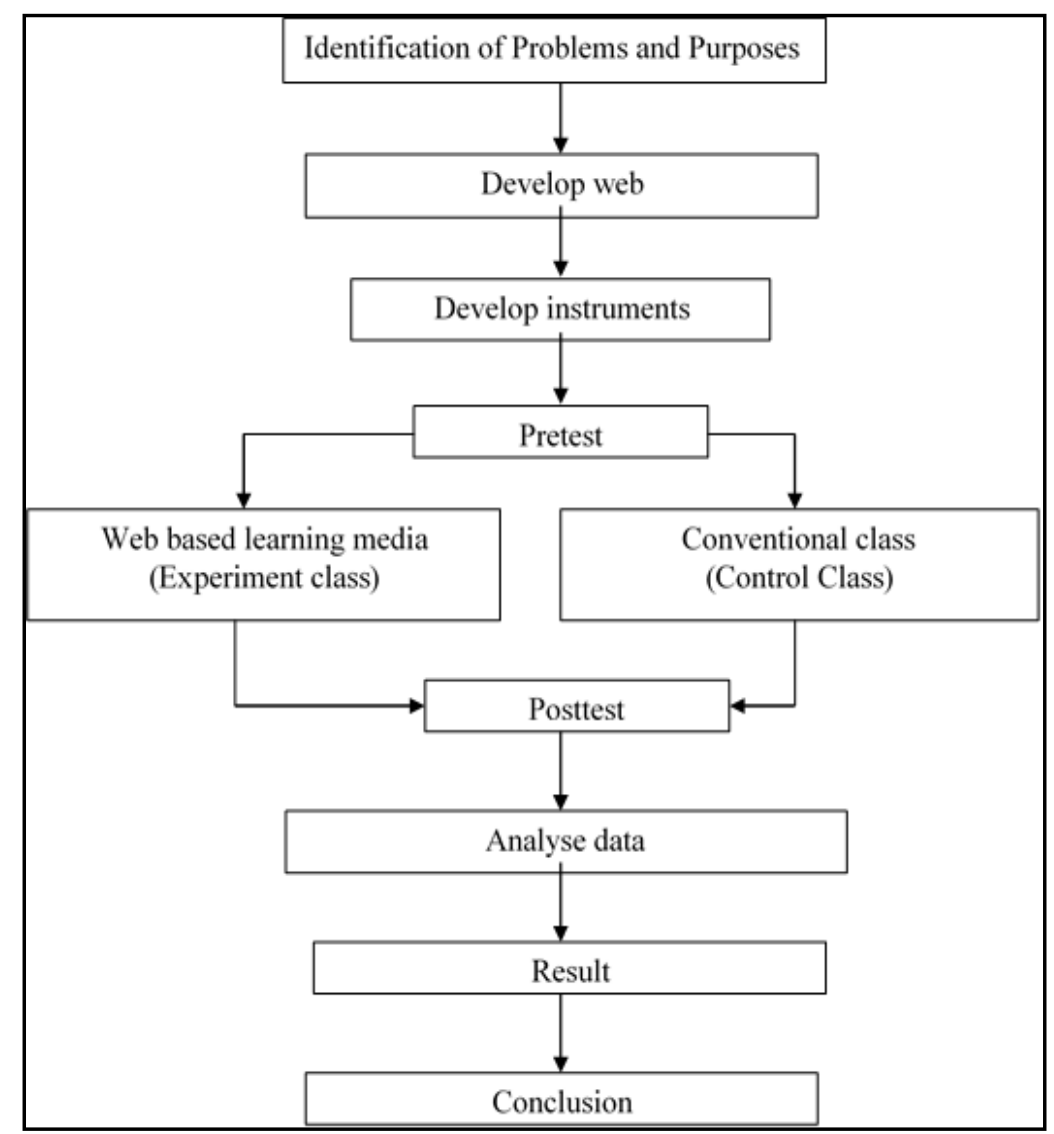

Figure 1. Flowchart of the study

\section{Data Analysis Technique}

The data obtained were classified into two groups, namely quantitative and qualitative data. The data analyses were performed using descriptive quantitative statistics to process data from the pre-test and post-test results. The effectiveness of web-based learning media with twodimensional space were analyzed by adapting the theory of Hake (1999) regarding normalized gain. The gain is the differences between the post-test and pre-test. It indicates the increase of students' concept mastery after the learning process. Hake (1999) formula for the value of the normalized gain is:

$$
g=\frac{\text { Posttest score }- \text { Pretest score }}{\text { Maximum Score }- \text { Pretest Score }}
$$

Large normalized gain is interpreted to declare the criteria of normalized gain.

Table 2.

Gain Score Classification

\begin{tabular}{ll}
\hline G Score & Interpretation \\
\hline $0.7<\mathrm{g}<1$ & High \\
\hline $0.3<\mathrm{g} .7$ & Medium \\
\hline $0<\mathrm{g}<0.3$ & Low \\
\hline
\end{tabular}




\section{Results}

The results showed that through analysis of statistical tests with SPSS 16.0 the early outcomes for control group and experimental group was the same (homogeneous). It could be seen from the average value of both groups and the pre-test results using t-test to see similarities of the two averages. The results showed that there was no significant difference between the initial outcomes of the experimental group and control group.

After the learning process was carried out, where the experimental group was treated using web-based learning media and the control group was treated with conventional learning media, the results showed that both groups experienced differences. Differences in the learning outcomes indicated by the average value of the experimental class was 86.09 , while the control group was 80.34 . From the average post-test results the learning outcomes of the experimental group were higher than the control group. The calculation of the normalized gain was used to determine the effectiveness of using web-based learning media with the experimental group against the use of conventional learning media. The results of the normalized gain values obtained for the control group was at 0,30 , while the value of $g$ for the experimental group is at 0.54. The value of $g$ above shows that the learning outcomes of the experimental group are higher than the control group.

\section{References}

Daryanto. (2010). Media pembelajaran. Yogyakarta: Gava Media.

Ha, J. H. (2011). Design of an effective learning evaluation component in web-based instruction. International Journal of Multimedia and Ubiquitous Engineering, 6(4), 112.

Hake, R. (1999). Analyzing change/gain scores. Retrieved from http://www.physics.indiana.edu/ sdi/AnalyzingChange-Gain.pdf 